\title{
Agreement near on new telescope in Namibia
}

Cape Town. Representatives from South Africa, Namibia and Germany are meeting this week in Windhoek to discuss plans to erect a 3.5-4.0-metre telescope on the Gamsberg, a flat-topped mountain $150 \mathrm{~km}$ southwest of the Namibian capital.

This has emerged as the most likely site for the Southern African Large Telescope (SALT), which has been on the drawing board for the past six years. The European Southern Observatory (ESO), based at Garching near Munich, is also interested in the site: it is the most favoured alternative site for the Very Large Telescope if land claims prevent its erection at Paranal in Chile (see Nature 370, 494; 1994). ESO officials have been conducting tests on atmospheric turbulence at Gamsberg since July.
The Namibian government has already granted outline approval for the project. The task of the meeting will therefore be to draft agreements between the three governments and the two institutions involved: the South African Foundation for Research Development (FRD) and the German Max Planck Institute for Astronomy, which is based in Heidelberg.

One day of the meeting will be spent inspecting the site itself. This is a plateau approximately $2 \mathrm{~km}$ square and 2,350 metres above sea level, which the Max Planck Institute bought in the early 1970 s from a local farmer.

South African scientists would prefer the telescope to be erected at the FRD's South African Astronomical Observatory (SAAO)

\section{Tokyo University puts levy on gifts}

Tokyo. Hiroyuki Yoshikawa, the president of Tokyo University, has won the approval of the university's senate to set up a special 'presidential fund' based on a one per cent levy on donations that faculty members receive each year from private industry.

The fund will amount to only $¥ 60$ million (US $\$ 600,000$ ) a year, and therefore represents a relatively modest step towards achieving greater financial autonomy both for Yoshikawa's office and for his university, which is the leading national university in Japan. But the move could have repercussions throughout Japan's university system. At present, Japan's national universities are strictly

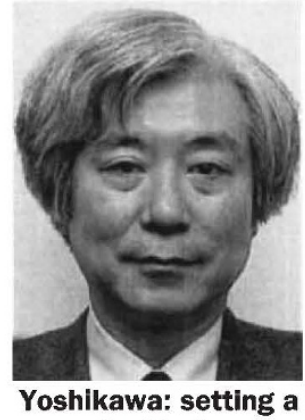
Yoshikawa: setting

regulated and financed by the Ministry of Education, Science and Culture. As a result, they have very limited general funds at their own disposal.

Donations from private industry provide a substantial source of funds for Japan's universities, amounting to more than $¥ 50$ billion a year. This is only slightly less than the government's annual budget for research grants distributed to universities by the ministry of education.

The money is given by industry chiefly to help it recruit good students from relevent departments. The donations grew rapidly during the bubble economy of the late 1980 s but growth has slowed during the recession (see Nature 360, 98; 1992).

But the money is distributed in tiny parcels averaging about $¥ 1$ million to indi- vidual faculty members, and is not pooled for the university as a whole. For example, the $¥ 6.17$ billion donated to Tokyo University last year was made up of 5,973 separate donations.

Unlike grants provided by the ministry of education, which can be used only for very narrowly defined purposes, researchers have considerable freedom in using their donations. One of the most common uses is for attending conferences and overseas travel, an area that receives poor support from the government.

By pooling a percentage of the donations, Yoshikawa will create a central fund free from the bureaucratic strings of the government. As such it is being welcomed as a dramatic step forward by reformists in universities and the government - and seems likely to be imitated by other universities.

But Yoshikawa's proposal has still faced strong opposition within the ranks of his own university. In particular, members of the faculty of engineering, of which Yoshikawa was dean before taking over the presidency, as well as those of the faculties of science and medicine, have opposed the idea.

Their opposition is not surprising, as these facilities receive by far the largest share of donations. In contrast, the proposal was warmly welcomed by other faculties, such as education and arts, which receive very few donations from industry.

For the present, the use of the fund will be limited by the senate to paying for overseas trips by faculty members undertaking study tours related to the formation of new institutes or organizations within the university. But Yoshikawa is hoping to use it for more general purposes in the future.

David Swinbanks at Sutherland, about $400 \mathrm{~km}$ northeast of Cape Town. But requests to the South African cabinet for funding over the past six years have not been approved.

"If the Germans are prepared to fund the telescope, and they have a preference for the Gamsberg, then we are happy with that", says Bob Stobie, director of SAAO and one of the South African representatives at the Windhoek meeting. Stobie adds that "Gamsberg is also a better site, but only marginally so".

A feasibility study by the SAAO has estimated the cost of the telescope at R95 million (US\$27 million). An additional R13 million would be required for developing the necessary infrastructure at the Gamsberg site (such infrastructure is already in place at Sutherland)

The SAAO was built jointly by Britain and South Africa in 1972, when its opening was attended by Lady (Margaret) Thatcher, then the UK secretary of state for education and science. But Britain suspended the joint programme in 1986 and has said that it is not prepared to contribute to the cost of a new telescope.

Under the terms of the new agreement between the FRD and the UK Particle Physics and Astronomy Research Council, a substantial amount of the British government's equipment that remained at Sutherland will now formally be handed over to South Africa.

Turbulence is the critical factor that can prevent angular resolution measured from the ground from approaching that which can be measured from space.

The main justification for the construction of the new telescope is that many objects, including the Large and Small Magellanic Clouds and the Milky Way, can be seen more easily from southern latitudes.

Longitude is also crucial; certain events may be observable only from the African continent, as other major southern land masses may be in daylight when they occur. In addition, observations from Africa can provide continuous coverage of certain astronomical phenomena.

The angular resolution of the new telescope will be an order of magnitude better than the existing one. This is only 1.9 metres long and is almost 50 years old, having first been erected at the Radcliffe Observatory in Pretoria in 1948, before being moved to Sutherland.

But policies on the allocation of time at Sutherland have allowed astronomers to make longer-scale observations than at most observatories, and this has contributed greatly to its success. Stobie feels that if used in a similar manner, the new 3.5-4metre telescope will even be able to compete with the new generation of 8 -metre telescopes.

Michael Cherry 